\title{
Efficacy of a nutritional education program to improve diet in patients attending a cardiac rehabilitation program: outcomes of a one-year follow-up
}

\author{
Maria Luisa Eliana Luisi - Barbara Biffi - Chiara Francesca Gheri • \\ Ennio Sarli • Elena Rafanelli • Emanuela Graziano - Sofia Vidali • \\ Francesco Fattirolli · Gian Franco Gensini · Claudio Macchi
}

Received: 6 August 2014/ Accepted: 5 February 2015/Published online: 28 February 2015

(C) SIMI 2015

\begin{abstract}
Dietary habits are widely reported to play a primary role in the occurrence of coronary artery disease (CAD). Cardiac rehabilitation is a multidisciplinary intervention that includes nutritional education. Proper nutrition plays an important role in cardiovascular health outcomes and in decreasing morbidity and mortality of cardiovascular diseases (CVD) as highlighted in the literature. The aim of this study was to assess the efficacy of an educational program to improve the diet of cardiac rehabilitation patients compared to usual treatment. 160 patients with CAD, (124 M, $36 \mathrm{~F})$ were randomized into two groups. Data analysis was conducted on 133 patients (11\% dropped out). All enrolled patients attended two educational seminars about proper nutrition and cardiovascular prevention, and completed a questionnaire about dietary habits (before CAD). The Body Mass Index (BMI) was calculated, and basal glycaemia and plasma lipids were assessed at the beginning and at the end of the study (12 months after hospital discharge). The intervention group patients underwent a mid-term evaluation of nutrient intakes, BMI, and received a personalized educational reinforcement by a dietitian. At the end of the study, the intervention group was shown to have significantly reduced their daily caloric intake (reduction of total proteins, total fat, carbohydrate,
\end{abstract}

\footnotetext{
M. L. E. Luisi ( $₫)$ · B. Biffi - C. F. Gheri - E. Rafanelli ·

E. Graziano - G. F. Gensini · C. Macchi

Don Gnocchi Foundation IRCCS, Florence, Italy

e-mail: mleluisi@mleluisi.it

E. Sarli

Progetti Live Surgery, Florence, Italy

S. Vidali · F. Fattirolli - G. F. Gensini - C. Macchi Department of Clinical and Experimental Medicine, University of Florence AOU Careggi, Florence, Italy
}

alcohol), and showed a significant reduction of weight and BMI compared to the control group. Individual nutritional counseling session as a reinforcement of a standard educational program is effective in reducing caloric intake and BMI, which may reduce cardiovascular risk factors in cardiovascular patients.

Keywords Multidisciplinary cardiac rehabilitation . Nutrition education - Cardiovascular prevention . Cardiovascular risk factors - Dietary habits . Cardiovascular follow-up

\section{Introduction}

Cardiovascular disease is one of the most common causes of death in both men and women who live in Western countries, and leads to increased healthcare costs [1]. According the World Health Organization (WHO), the major risk factors of cardiovascular disease are (in rank order) smoking, hypertension, high cholesterol levels, physical inactivity, obesity and diabetes mellitus.

Importantly, several of these risk factors can be ameliorated through lifestyle modification that incorporates a healthy diet [2-4].

A number of studies have demonstrated the protective effect of the Mediterranean diet, which includes the following dietary factors: high intakes of locally grown, fresh and seasonal fruits (including nuts but not peanuts), and vegetables (except potatoes, corn and green peas, considered starchy vegetables), whole cereals, legumes, fish, lowfat dairy products, olive oil, a moderate consumption of red wine, minimal consumption of full-fat dairy products, processed foods rich in sodium, sugar and saturated fatty acids [2]. 
The WHO has defined Cardiac Rehabilitation as the "sum of activity and interventions required to ensure the best possible physical, mental, and social conditions so that patients with chronic or post-acute cardiovascular disease may, by their own efforts, preserve or resume their proper place in society and lead an active life" $[5,6]$.

Nutritional education is an essential component of a cardiac rehabilitation program, and plays an important role in the prevention and management of obesity, dyslipidemias, hypertension and diabetes mellitus [7].

"In the usual care setting, compliance with lifestyle recommendations and treatment regimens starts to decline within 6 months after discharge from the hospital. Adherence to behavioral advice (diet, exercise and smoking cessation), after an acute coronary syndrome, is associated with a substantially lower risk of recurrent cardiovascular events compared with non adherence" [2].

Patients with cardiovascular disease after hospital discharge often return to physically inactive lives and an unhealthy diet. This happens because lifestyle modifications are difficult to maintain in adult patients. Because of the high rate of relapse to unhealthy lifestyles, patients at high risk of cardiovascular disease may benefit from continued support and education for important diet and behavioral modifications [8, 9].

The aim of the study was to assess the effectiveness of a nutritional education intervention program at 6 months of discharge compared with the usual educational program adopted at the Don Carlo Gnocchi Foundation of Florence, Cardiac Rehabilitation Unit for patients affected by coronary artery disease (CAD).

\section{Materials and methods}

Study design and patient population

After admission to the Cardiac Rehabilitation Unit of Don Carlo Gnocchi Foundation of Florence, patients diagnosed with $\mathrm{CAD}$ were recruited and randomized to either the intervention group (IG) or the control group (CG).

Both the IG and the $\mathrm{CG}$ performed a rehabilitation program that consisted of two one-hour sessions per day of physical exercise for 5 days a week as described in articles published by our working group, a psychosocial intervention and a nutritional counseling [10, 11].

Patients with dementia, severe cognitive impairment and neurological limitations were not included in the study. Prior to hospitalization, none of the recruited patients participated in a weight-loss program.

All participants were informed of the purpose of the study, and were provided written informed consent.
During hospitalization, all patients attended two onehour nutritional education meetings. The first meeting was led by a dietitian, and focused on basic dietary information (nutritional classification of carbohydrates, lipids and proteins and an explanation of their different metabolic functions.) The second meeting was led by an endocrinologist, and focused on European Guidelines on healthy nutrition in cardiovascular diseases prevention [12]. In addition, all patients participated in a multidisciplinary educational meeting (physician, dietitian, psychologist and physiotherapist) where modifiable and nonmodifiable risk factors for cardiovascular diseases were explained.

At admission, study participants submitted anthropometric and dietetic assessments. Dietary habits were gathered by the Indali validated questionnaire, and an evaluation of anthropometric (height, weight, waist circumference and BMI), and biochemical (glycemia, total cholesterol, HDL cholesterol, LDL cholesterol and triglycerides) parameters were performed [13]. This assessment was repeated at a 12-month follow-up.

Intervention group patients returned to the Dietetic Service 6 months after discharge, at which time a dietitian evaluated their diet and anthropometric data. Following the dietitian's evaluation, each patient received an individual diet counseling session with a review of dietary habits and goals [9].

\section{Anthropometric measures}

Height was measured on a wall-mounted stadiometer, and weight was measured on a leveled platform scale.

Waist circumference was measured in the mid-point between the 12th rib and the iliac crest.

BMI was calculated as [weight $(\mathrm{Kg})] /[\text { height }(\mathrm{m})]^{2}$.

Eating habits

Food behavior was evaluated by a validated Indali questionnaire to determine the intake of various nutrients. The survey items reported the quantities and frequency of food consumption (cereals, vegetables and fruit, beans, fish, poultry, dairy products, milk, fats and oils, eggs, meat, sweets, salt, alcohol and other beverages) [13].

\section{Biochemical essays}

The participants were checked at our reference laboratory, the San Lorenzo Institute. Blood samples were collected in the morning after a night fast. Concentrations of plasma fasting glucose, total cholesterol, HDL cholesterol and serum triglycerides were determined using commercial kits (Glucose-Beckman-Coulter, Cholesterol-Beckman- 
Coulter, HDL-Sentinel Diagnostic and TR-BeckmanCoulter) on an automated analyzer (DXC-600, BeckmanCoulter). LDL cholesterol was calculated by use of the Friedewald formula: [LDL cholesterol] $=$ [Total cholesterol] - [HDL cholesterol] - [triglycerides]/5, where all concentrations are given in $\mathrm{mg} / \mathrm{dl}$.

\section{Statistical analysis}

After the first phase of data management and the evaluation of all values, the analysis of demographic variables, clinical data, biochemical parameters and nutrients significant to the study were performed by the statistical software package for social sciences, SPSS version 10 (SPSS Inc. 2003, Chicago, IL, USA).

The following were performed for the continuous variables: mean \pm standard deviation (SD), median, values range, minimal and maximum value/mean \pm standard deviation (SD), median, values range and minimum and maximum value. For the categorical variables relative (\%) and absolute frequencies were performed.

A $T$ test was performed (on independent and paired samples,) to test the differences within intervention group and control group first at baseline and then at follow-up. A Chi square test was performed on all patients to evaluate possible links between clinical asset (metabolic diseases and cardiovascular diseases) gender, education and intervention-control group at baseline and follow-up.

Study hypotheses were tested at the 0.05 statistical significance level for the two-tailed test.

\section{Results}

A total of 160 patients (124 men and 36 women) were recruited into the study. The drop-out rate was $11 \%$ (7 patients died and 20 patients voluntarily left the study), leaving 133 patients (99 men and 34 women), available for final analysis. A total of 67 were randomized to the intervention group (IG) while 66 were placed into the control group (CG). Table 1 outlines the demographics and clinical characteristics of the study population; the groups were generally similar however participants in the IG were more likely to be obese and have diabetes mellitus, and less likely to have dyslipidemia. Table 2 reveals no significant differences between the groups at baseline and at 12-month follow-up with regard to weight, BMI, waist circumference, glucose, cholesterol (total, HDL and LDL) and triglycerides.

Compared with baseline, the IG had a significant reduction in weight $(P=0.001)$ and BMI $(P=0.001)$ and a significant increase in total serum cholesterol $(P=0.001)$, HDL $(P=0.001)$ and fasting glucose $(P=0.042)$.

The CG had a significant increase in waist circumference $(P=0.008)$, total serum cholesterol $(P=0.001)$, HDL $(P=0.001)$ and LDL $(P=0.025)$. At 1 -year followup, there were significant differences between the two groups with respect to diet, revealing a significant reduction in nutrients and caloric intake in the IG (Table 3). Specifically, there were significant reductions in calories $(P=0.001)$ in the $\mathrm{IG}$ versus the $\mathrm{CG}$ particularly in total and animal proteins intake $(P=0.012$ and $P=0.011$, respectively), saturated and monounsaturated fat intake ( $P=0.001$ and $P=0.001$, respectively), and in soluble and available carbohydrate intake $(P=0.007$ and $P=0.009$, respectively).

Compared to baseline, the IG reduced calories (2,218 kcal/day at baseline vs. $1,727 \mathrm{kcal} /$ day at follow-up, $P=0.001)$ and alcohol intake (18.66 vs. $11 \mathrm{~g}, P=0.012)$. The IG also reduced all nutrients: total proteins $(P=0.001)$, animal proteins $(P=0.027)$, total fat $(P=0.001)$, saturated fat $(P=0.001)$, monounsaturated fat $(P=0.001)$, soluble carbohydrate $(P=0.001)$ and available carbohydrate $(P=0.016)$ (Table 3$)$ compared to baseline levels.

There were no significant differences for folic acid at baseline and at 12-month follow-up within each group and between groups.
Table 1 Demographics and clinical characteristics of the study population

* From Pearson “ $\chi^{2}$ ” test

\begin{tabular}{llll}
\hline Characteristics & CG $(n=66)$ & IG $(n=67)$ & $\begin{array}{l}\text { Between-group } \\
\text { comparisons at } \\
\text { baseline } P^{*}\end{array}$ \\
\hline Age (years) & $68.9 \pm 9.3$ & $68.9 \pm 10.33$ & \\
Gender (male/female) & $47 \mathrm{M}+19 \mathrm{~F}$ & $52 \mathrm{M}+15 \mathrm{~F}$ & \\
Hypertension & $69 \%$ & $59 \%$ & 0.228 \\
Diabetes & $33 \%$ & $35 \%$ & 0.763 \\
Obesity & $22.7 \%$ & $38.8 \%$ & 0.045 \\
Hypercholesterolemia & $12 \%$ & $17 \%$ & 0.350 \\
Hypertriglyceridemia & $1.5 \%$ & $0 \%$ & 0.312 \\
Dyslipidemia & $42 \%$ & $23 \%$ & 0.023 \\
\hline
\end{tabular}


Table 2 Changes in anthropometric and biochemical parameters at baseline and at 12-month follow-up for the IG and CG

\begin{tabular}{|c|c|c|c|c|c|c|c|c|}
\hline \multirow[t]{3}{*}{ Characteristics } & \multicolumn{2}{|l|}{$\mathrm{CG}$} & \multirow{2}{*}{\multicolumn{2}{|c|}{ IG }} & \multirow{3}{*}{$\begin{array}{l}\text { Between- } \\
\text { group } \\
\text { comparisons } \\
\text { (baseline) } \\
p^{*}\end{array}$} & \multirow{3}{*}{$\begin{array}{l}\text { Between-group } \\
\text { comparisons } \\
\text { (follow up } \\
12 \text { months) } \\
p^{*}\end{array}$} & \multicolumn{2}{|c|}{$\begin{array}{l}\text { Intra-group } \\
\text { comparisons }\end{array}$} \\
\hline & & & & & & & \multirow{2}{*}{$\begin{array}{l}\mathrm{CG} \\
p^{* *}\end{array}$} & \multirow{2}{*}{$\begin{array}{l}\mathrm{IG} \\
p^{* *}\end{array}$} \\
\hline & Baseline & $\begin{array}{l}\text { Follow-up } \\
12 \text { months }\end{array}$ & Baseline & $\begin{array}{l}\text { Follow-up } \\
12 \text { months }\end{array}$ & & & & \\
\hline Bodyweight (kg) & $77.56 \pm 13.28$ & $76.33 \pm 12.27$ & $79.29 \pm 13.62$ & $76.66 \pm 12.7$ & 0.462 & 0.878 & 0.052 & 0.001 \\
\hline BMI $\left(\mathrm{kg} / \mathrm{m}^{2}\right)$ & $27.5 \pm 4.20$ & $27.11 \pm 3.93$ & $28.73 \pm 4.05$ & $27.82 \pm 3.97$ & 0.094 & 0.301 & 0.074 & 0.001 \\
\hline $\begin{array}{l}\text { Waist } \\
\text { circumference }(\mathrm{cm})\end{array}$ & $97.83 \pm 11.96$ & $99.98 \pm 10.9$ & $100.1 \pm 11.0$ & $100.5 \pm 10.5$ & 0.286 & 0.800 & 0.008 & 0.615 \\
\hline $\begin{array}{l}\text { Fasting glucose } \\
(\mathrm{mg} / \mathrm{dl})\end{array}$ & $118.3 \pm 37.62$ & $106.0 \pm 34.3$ & $109.2 \pm 31.9$ & $122.6 \pm 52.5$ & 0.253 & 0.071 & 0.855 & 0.042 \\
\hline $\begin{array}{l}\text { Total cholesterol } \\
(\mathrm{mg} / \mathrm{dl})\end{array}$ & $149.0 \pm 35.9$ & $178.1 \pm 48.2$ & $151.5 \pm 35.6$ & $177.1 \pm 49.5$ & 0.705 & 0.920 & 0.001 & 0.001 \\
\hline $\begin{array}{l}\text { HDL cholesterol } \\
(\mathrm{mg} / \mathrm{dl})\end{array}$ & $34.69 \pm 8.21$ & $47.8 \pm 12.3$ & $35.0 \pm 8.49$ & $47.3 \pm 13.8$ & 0.824 & 0.842 & 0.001 & 0.001 \\
\hline $\begin{array}{l}\text { LDL cholesterol } \\
(\mathrm{mg} / \mathrm{dl})\end{array}$ & $87.3 \pm 29.8$ & $100.7 \pm 38$ & $87.3 \pm 31.7$ & $98.2 \pm 43.4$ & 0.997 & 0.759 & 0.025 & 0.075 \\
\hline Triglycerides (mg/dl) & $135.3 \pm 79.4$ & $167.2 \pm 247.2$ & $132.9 \pm 61.98$ & $140.0 \pm 92.4$ & 0.857 & 0.464 & 0.400 & 0.265 \\
\hline
\end{tabular}

* From Student " $t$ " test for independent samples

** From paired Student " $t$ " test

Table 3 Energy and nutrients intake at baseline and at 12 months follow-up for the IG and CG

\begin{tabular}{|c|c|c|c|c|c|c|c|c|}
\hline \multirow[t]{3}{*}{ Characteristics } & \multirow{2}{*}{\multicolumn{2}{|c|}{ CG }} & \multirow{2}{*}{\multicolumn{2}{|c|}{ IG }} & \multirow{3}{*}{$\begin{array}{l}\text { Between- } \\
\text { group } \\
\text { comparisons } \\
\text { (baseline) } \\
p^{*}\end{array}$} & \multirow{3}{*}{$\begin{array}{l}\text { Between- } \\
\text { group } \\
\text { comparisons } \\
\text { (follow up } \\
12 \text { months) } \\
p^{*}\end{array}$} & \multicolumn{2}{|c|}{$\begin{array}{l}\text { Intra-group } \\
\text { comparisons }\end{array}$} \\
\hline & & & & & & & \multirow{2}{*}{$\begin{array}{l}\text { CG } \\
p^{* *}\end{array}$} & \multirow{2}{*}{$\begin{array}{l}\mathrm{IG} \\
p^{* *}\end{array}$} \\
\hline & Baseline & $\begin{array}{l}\text { Follow-up } \\
12 \text { months }\end{array}$ & Baseline & $\begin{array}{l}\text { Follow-up } \\
12 \text { months }\end{array}$ & & & & \\
\hline Total proteins (g) & $76.89 \pm 17.7$ & $76.3 \pm 17.6$ & $78.3 \pm 22.8$ & $68.7 \pm 16.4$ & 0.683 & 0.012 & 0.767 & 0.001 \\
\hline $\begin{array}{l}\text { Animal } \\
\text { proteins }(\mathrm{g})\end{array}$ & $43.31 \pm 13.4$ & $42.9 \pm 13.0$ & $41.5 \pm 14.3$ & $37.6 \pm 10.5$ & 0.466 & 0.011 & 0.827 & 0.027 \\
\hline Total fat (g) & $74.3 \pm 25.4$ & $73.9 \pm 15.9$ & $79.6 \pm 22.0$ & $55.8 \pm 19.8$ & 0.205 & 0.001 & 0.904 & 0.001 \\
\hline Saturated fat $(\mathrm{g})$ & $20.7 \pm 7.3$ & $20.3 \pm 5.6$ & $21.8 \pm 7.8$ & $15.7 \pm 7,6$ & 0.409 & 0.001 & 0.674 & 0.001 \\
\hline $\begin{array}{l}\text { Monounsaturated } \\
\text { fat }(\mathrm{g})\end{array}$ & $39.0 \pm 14.2$ & $39.5 \pm 9.9$ & $42.0 \pm 13.3$ & $28.2 \pm 11.7$ & 0.200 & 0.001 & 0.802 & 0.001 \\
\hline $\begin{array}{l}\text { Soluble } \\
\text { carbohydrate (g) }\end{array}$ & $270.2 \pm 82.2$ & $272.1 \pm 93.4$ & $280.3 \pm 83.2$ & $230.5 \pm 80.8$ & 0.484 & 0.007 & 0.836 & 0.001 \\
\hline $\begin{array}{l}\text { Available } \\
\text { carbohydrate }(\mathrm{g})\end{array}$ & $72.1 \pm 41.7$ & $78.3 \pm 33.6$ & $74.8 \pm 29.0$ & $63.7 \pm 25.9$ & 0.670 & 0.009 & 0.133 & 0.016 \\
\hline Energy (Kcal) & $2112.58 \pm 509.5$ & $2117.0 \pm 502.8$ & $2218.03 \pm 567.0$ & $1726.8 \pm 495.5$ & 0.262 & 0.001 & 0.926 & 0.001 \\
\hline Folic acid (g) & $383.6 \pm 183,7$ & $408.3 \pm 187,7$ & $420.56 \pm 214.3$ & $456.24 \pm 200.9$ & 0.289 & 0.158 & 0.314 & 0.189 \\
\hline Alcohol (g) & $16.76 \pm 22.98$ & $16.94 \pm 24.82$ & $18.66 \pm 24.05$ & $11.49 \pm 16.85$ & 0.642 & 0.141 & 0.940 & 0.012 \\
\hline
\end{tabular}

* From Student " $t$ " test for independent samples

** From paired Student " $t$ " test

\section{Discussion}

Our study was designed to test the effectiveness of an educational program to improve dietary habits in patients with cardiovascular disease compared to the usual treatment.
At 6 months after hospital admission, patients in the IG attended individual diet counseling sessions focused on nutritional goals. At the 12-month follow-up, patients in the IG showed better nutritional habits (more adherent to the Mediterranean diet), and lower BMI compared to 
patients in the CG. The IG had significant improvement at follow-up in terms of nutrient intake and reduction of calories/day and alcohol intake. The reduction of monounsaturated fat intake in the IG at follow-up is related to the reduction of total lipid intake. Furthermore, the monounsaturated fatty acid percentage of total energy is similar in both groups at baseline and follow-up, and reflects the ATP III and the EHN recommendations $[12,14]$.

Our hypothesis was, therefore, confirmed as the IG's dietary habits revealed improvement with a corresponding reduction of weight and BMI.

However, we also found a statistically significant worsening of some biochemical values-fasting glucose, total cholesterol and LDL cholesterol in the IG. We observed an HDL cholesterol increase at follow-up in both IG and CG, but triglycerides did not show any statistically significant differences between the two groups at follow-up. The worsening laboratory values in the IG may have been related to a known decline in compliance with pharmacological therapy after hospital discharge as described in literature $[2,15]$. Our study design focused on nutritional habits, and not on pharmacological therapy. We will consider this important parameter in a future protocol. Our study has several limitations: one is the small number of individual diet counseling sessions that have demonstrated to be one of the most effective ways to help the patients in maintaining healthy dietary habits; the other important limitation is that we could not evaluate the link between drug therapy and biochemical data [16].

A recent study suggests that behavioral goals are easier to attain than biochemical targets likely because patient behavior can be self-monitored [17]. The success of our educational intervention might be attributed to the patients' ability to acquire the skills and strategies to attain individualized behavioral goals during the 6-month intervention. While the role of proper nutrition in achieving and maintaining optimal health is widely recognized, further research is necessary to develop nutrition protocols to improve patient compliance and health status, and thereby improve cardiovascular disease prevention. The scientific community needs to give it proper attention through the formulation of a formal protocol, followed and recognized by physicians, dietitians and patients.

Acknowledgments The authors gratefully acknowledge the financial support of the Foundation Ente Cassa di Risparmio of Florence.

\section{Conflict of interest None.}

Ethical standards The Ethics Committee approved the study that has been performed in accordance with the ethical standards laid down in the 1964 Declaration of Helsinki and its later amendments.

\section{References}

1. Lloyd-Jones DM, Hong Y, Labarthe D, Mozaffarian D, Appel LJ, Van Horn L, Greenlund K, Daniels S, Nichol G, Tomaselli GF, Arnett DK, Fonarow GC, Ho PM, Lauer MS, Masoudi FA, Robertson RM, Roger V, Schwamm LH, Sorlie P, Yancy CW, Rosamond WD (2010) Defining and setting national goals for cardiovascular health promotion and disease reduction: the American Heart Association's strategic Impact Goal through 2020 and beyond. Circulation 121:586-613

2. Perk J, De Backer G, Gohlke H, Graham I, Reiner Z, Verschuren M, Albus C, Benlian P, Boysen G, Cifkova R, Deaton C, Ebrahim S, Fisher M, Germano G, Hobbs R, Hoes A, Karadeniz S, Mezzani A, Prescott E, Ryden L, Scherer M, Syvänne M, Scholte op Reimer WJ, Vrints C, Wood D, Zamorano JL, Zannad F, European Association for Cardiovascular Prevention \& Rehabilitation (EACPR); ESC Committee for Practice Guidelines (CPG). European guidelines on cardiovascular disease prevention in clinical practice (version 2012) (2012) The fifth joint task force of the European Society of Cardiology and other societies on cardiovascular disease prevention in clinical practice (constituted by representatives of nine societies and by invited experts). Eur Heart J 33:1635-1701

3. Estruch R, Martinez-Gonzalez MA, Corella D, Salas-Salvado J, Ruiz-Gutierrez V, Covas MI, Fiol M, Gomez-Gracia E, LopezSabater MC, Vinyoles E, Aros F, Conde M, Lahoz C, Lapetra J, Saez G, Ros E (2006) Effects of a mediterranean-style diet on cardiovascular risk factors: a randomized trial. Ann Intern Med 145:1-11

4. Rotilio G, Berni Canani R, Barba G, Branca F, Cairella G, Dilaghi B, Fieschi C, Garbagnati F, Gentile MG, Gensini GF, Gualtieri A, Inzitari D, La Massa M, Luisi ML, Mancia G, Marcelli M, Masini ML, Mastrilli F, Paolucci S, Pratesi L, Rubba P, Sacchetti ML, Salvia A, Scalfi L, Scognamiglio U, Siani A, Strazzullo P (2004) Nutritional recommendations for the prevention of ischemic stroke. Nutr Metab Cardiovasc Dis 14:115-120

5. WHO Expert Committee on Rehabilitation after Cardiovascular Diseases, With Special Emphasis on Developing Countries (1993) Rehabilitation after cardiovascular diseases, with special emphasis on developing countries: report of a WHO Committee. World Health Organ Tech Rep Ser 831:1-122

6. Agostini S, Biffi B, Brazzo S, da Vico L, Masini ML, Scapolo M (2008) The role of dietitian in cardiac rehabilitation and prevention. Monaldi Arch Chest Dis 70:107-111

7. Leon AS, Franklin BA, Costa F, Balady GJ et al (2005) Cardiac rehabilitation and secondary prevention of coronary heart disease. Circulation 111:369-376

8. Janssen V, De Gucht V, Dusseldorp E, Maes S (2013) Lifestyle modification programmes for patients with coronary heart disease: a systematic review and meta-analysis of randomized controlled trials. Eur J Prev Cardiol 20:620-640

9. Timlin MT, Shores KV, Reicks M (2002) Behavior change outcomes in an outpatient cardiac rehabilitation program. J Am Diet Assoc 102:664-671

10. Molino-Lova R, Prisco D, Pasquini G, Vannetti F, Paperini A, Zipoli R, Luisi ML, Cecchi F, Macchi C (2013) Higher uric acid levels are associated with better functional recovery in elderly patients receiving cardiac rehabilitation. Nutr Metab Cardiovasc Dis. 23(12):1210-1215

11. Polcaro P, Lova RM, Guarducci L, Conti AA, Zipoli R, Papucci M, Garuglieri S, Raimo D, Fattirolli F, Macchi C, Gensini GF (2008) Left-ventricular function and physical performance on the 6-min walk test in older patients after inpatient cardiac rehabilitation. Am J Phys Med Rehabil 87(1):46-52 
12. European Heart Network (2011) Diet, physical activity and cardiovascular disease prevention in Europe

13. Alberti-Fidanza A, Paolacci CA, Chiuchiu MP, Coli R, Parretta MG, Verducci G, Fidanza F (1994) Dietary studies on two rural italian population groups of the Seven Countries Study. 2. Concurrent validation of protein, fat and carbohydrate intake. Eur J Clin Nutr 48:92-96

14. Expert Panel on Detection (2001) Evaluation, and treatment of high blood cholesterol in adults. Executive summary of The Third Report of The National Cholesterol Education Program (NCEP) expert panel on detection, evaluation, and treatment of high blood cholesterol in adults (Adult Treatment Panel III). JAMA 285(19):2486-2497

15. Lear SA, Ignaszewski A, Linden W, Brozic A, Kiess M, Spinelli JJ, Haydn Pritchard P, Frohlich JJ (2003) The extensive lifestyle management intervention (ELMI) following cardiac rehabilitation trial. Eur Heart J 24(21):1920-1927
16. Arcand JA, Brazel S, Joliffe C, Choleva M, Berkoff F, Allard JP, Newton GE (2005) Education by a dietitian in patients with heart failure results in improved adherence with a sodium-restricted diet: a randomized trial. Am Heart J 150(4):716

17. Artinian NT, Fletcher GF, Mozaffarian D, Kris-Etherton P, Van Horn L, Lichtenstein AH, Kumanyika S, Kraus WE, Fleg JL, Redeker NS, Meininger JC, Banks J, Stuart-Shor EM, Fletcher BJ, Miller TD, Hughes S, Braun LT, Kopin LA, Berra K, Hayman LL, Ewing LJ, Ades PA, Durstine JL, Houston-Miller N, Burke LE (2010) Interventions to promote physical activity and dietary lifestyle changes for cardiovascular risk factor reduction in adults: a scientific statement from the American Heart Association. Circulation 122:406-444 